\title{
A COMPARISON OF WEAR RATES OF BALL MILL GRINDING MEDIA
}

\author{
A. Jankovic", T. Wills, S. Dikmen \\ Metso Process Technology and Innovation, Brisbane, Australia \\ Queensland Centre for Advanced Technologies, 1 Technology Court, \\ Pullenvale, QLD 4069 Australia
}

(Received: February 1, 2016; Accepted: November 4, 2016)

\begin{abstract}
The Ball Mill Abrasion (BMA) test was developed by the University of Queensland Materials Performance group to simulate the high stress abrasion conditions experienced in production ball mills. It gives accurate predictions of the service life of wear resistant alloys in mill liner and grinding media applications. In this paper the BMA test methodology was applied to investigate the wear rates of four grades of grinding media using two small laboratory ball mills. The rankings obtained from the tests were identical with those from the full BMA test, although the difference between the different grades was not as marked. It is concluded that untrained personnel can use a simple small-scale procedure to evaluate relative but not absolute grinding media wear rates.
\end{abstract}

Key words: grinding media; wear rate; ball mill abrasion test.

\section{Introduction}

Grinding media should be produced to provide the greatest performance that is the lowest wear rate and highest grinding transfer to cost ratio. Ball producers utilise different manufacturing methods, based on the properties, size and chemical composition of the product. Major ball forming techniques include cold and hot die forging, roll and skew roll forging, and die and sand casting. Balls for different milling environments require different properties, which influence the choice of manufacturing process.

SAG mill balls experience both significant abrasive and impact wear due to their large $(75-100 \mathrm{~mm})$ diameters. Ball mill balls experience a greater number of impacts, but at lower magnitude than SAG mill balls, due to the smaller ball size, and smaller mill diameter. Feeds are typically highly abrasive, contributing $10-15 \mu \mathrm{m} / \mathrm{hr}$ wear for softer ores and $20 \mu \mathrm{m} / \mathrm{hr}$ for abrasive gold, copper and molybdenum ores [1]. Media requires maximum abrasive wear resistance, with suitable toughness and impact resistance, especially in grate discharge mills where the pulp level approaches zero at discharge.

Secondary ball mill balls experience significant levels of abrasive and corrosive wear, with insignificant levels of impact wear due to the small $2.5-60 \mathrm{~mm}$ diameters. They experience $25-40 \%$ less wear than in primary grinding of the same ore. High chromium balls may be economical for high levels of corrosive wear, preventing pitting, as they experience $25-30 \%$ less wear than forged steel, and up to $50 \%$ less wear in corrosive applications [1].

Media consumption and failure is governed by both intrinsic and extrinsic factors. Ore hardness, feed size, product size, pulp density, pulp level, mill size and speed and throughput are intrinsic factors, while

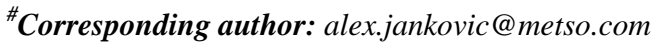


media quality is the extrinsic factor. Ball failures such as surface spalling, loss of shape, shelling, capping and halving may be caused by variations in chemistry, hardness or structure [2]. Quality control processes from both manufacturer and consumer are integral to maintaining media quality.

Common manufacturing issues include change in chemistry, composition or heat treatment, hydrogen cracking, delayed austenite transformation, residual stress, deformation stress, ductile brittle transition and pre-existing forging or casting defects [3].

Internal defects may be caused as a result of the quenching and hardening processes. Rapid quenching produces transient thermal stress, which may cause cracks, and variation in microstructure below the surface that may cause further residual stress due to density difference. Delayed transformation of martensite due to impact or low temperature will also create internal stress, and dissolved hydrogen from casting may migrate and accumulate internal pressure [3]. Stress may also be caused in forged balls by centreline shrinkage in bar prior to forging, or by forge laps [2].

Both cast and forged media may display defects, and the integrity of the media must be determined prior to property testing. Generally a statistically appropriate number of balls are inspected for external defects, and are sectioned to determine internal defects. Casting defects include shrinkage and gas porosity, creating internal voids and effecting impact and abrasion characteristics, and forging defects include pits, soft spots, cuts, flat areas and out of round protrusions,

Further defects may be caused by delayed austenite-martensite transformation of retained austenite, induced by low temperature or impact. This occurrence may cause internal stress and ball bursting during storage or operation. This effect is investigated through $\mathrm{X}$-ray diffraction testing on samples near the ball surface to determine the austenite percentage. Austenite at $10 \mathrm{wt}$. $\%$ is widely considered the maximum allowable content for impact related applications [2]. Austenite inclusion above 10 $\%$ will result in impact failures, such as macro spalling experienced at $15 \%$ austenite and ball splitting.

Important grinding media quality parameters include size, mass, chemistry, hardness, microstructure, toughness, internal stress and worn size distribution. Size and mass may be tested on a statistically representative number of balls through simple sampling methods. Ball chemistry is routinely determined as it affects performance and microstructure. Commonly the manufacturing report will show results from spark emission spectrometry which offers extremely fast and simple detection of more than 40 elements in metals and alloys to ppm level resolution.

A number of methods exist to measure hardness, the three used most commonly in the testing of grinding media or liner material are the Brinell, Rockwell and Vickers hardness tests. Hardness testing is conducted by most grinding ball producers, as for constant microstructure hardness correlates directly with abrasive wear resistance, which is important in all milling applications. Large diameter balls such as SAG balls, may exhibit significant hardness gradients either intentionally or unintentionally. Balls larger than 3 inches $(76 \mathrm{~mm})$ in diameter may exhibit structural variation due to the larger distance to be cooled through under rapid quenching. The hardness gradient may be detrimental to performance, or if intentional may be exploited to manipulate the ball size distribution - providing rapid wear to the core such that a large ball worn to an unsuitable size is ground out quickly [3]. A hardness gradient is unwanted in smaller balls and may occur due to issues in the quenching and cooling processes. Due to the possible 
occurrence of hardness gradients, hardness testing should be undertaken not only on the ball surface, but also on the surfaces of crosssectional slices, which may also be used for inspection of microstructure and internal defects. Generally forged balls exhibit larger hardness gradients than cast balls [2].

Impact testing for grinding balls is usually conducted by a ball on ball impact test using specialised equipment; however standard pendulum and drop weight impact tests may also be used for comparative purposes for quality control. Abrasion testing is also often carried out at laboratory scale for quality control purposes. A small continuous laboratory mill is used, with ore and water added to achieve a suitable mill pulp density. Balls are tested for 100 hours, with the balls removed and their mass measured every 20 hours [2]. Mass loss is calculated with time and the slope comprises the wear rate.

Numerous tests have been devised to characterise grinding media performance. Tests carried out at laboratory scale use various mechanical devices to measure media wear indirectly, while plant scale tests involve directly determining the wear of specially marked balls.

\section{Indirect wear tests}

The Bond abrasion index test was first developed in 1956 and is still in use today. The test produces an index value, which is then used in a formula to provide the metal wear rate for a particular piece of equipment expressed as pounds of metal worn per $\mathrm{kWh}$ of comminution energy used. The test measures the weight loss of a steel paddle which continuously impacts falling ore particles for one hour under a standardised testing condition [4]. The paddle comprises a flat $3 \times 1 \times 0.25$ inch piece of SAE chromenickel-moly steel hardened to 500 Brinell. Feed sample requirements for testing are 1.6 $\mathrm{kg}$ of $-0.75+0.5$ inch ore. The paddle is weighed after the test to $\pm 0.1 \mathrm{mg}$ and the weight loss in grams is the abrasion index $\mathrm{Ai}$ for the material.

\section{Direct wear tests}

The marked ball wear test (MBWT) is a widely used standardised test for media performance. It offers a reliable approach for comparison of wear rates of different materials under identical conditions. Media to be tested is charged into the operating plant mill. The samples are weighed prior to charging and marked for later recovery. Marking media for recovery may be done by drilling several holes or slits in different numbers, sizes and geometries, or by drilling a hole to insert a marked tag, which is then sealed by a low melting point alloy which will melt in hot water, releasing the tag [5]. Marking is performed with care to prevent localised change in microstructure or mechanical properties due to heat, and balls are recovered during shutdowns and reweighed to determine wear.

The impact of corrosive wear in industrial operations is significant. Industrial experience with cast chrome iron media has raised concerns that wear performance depends on the mill environment, defined by ore type and water quality. Anecdotal evidence suggests that the MBWT may inflate the predicted benefit of chrome iron media compared to low alloy steel. The gains suggested by using a small number of balls during trials were not achieved at full charge. Laboratory MBWT have been conducted to determine the effects of mill salinity and $\mathrm{pH}$ and galvanic corrosion effects and to characterise the affect of corrosions [6]. For the ore tested the findings were that $13-20 \%$ of the wear could be attributed to corrosion, the mill environment did not affect wear, and the variability seen in 
chrome media wear may be at least partially attributed to galvanic effects.

The Ball Mill Abrasion (BMA) test is a non-standardised test developed by the University of Queensland Materials Performance group (UQMP) to simulate the high stress abrasion conditions experienced in production ball mills. It gives accurate predictions of the service life of wear resistant alloys in mill liner and grinding media applications [7]. The BMA test offers superior simulation of real mill conditions, closely reproducing abrasive particle and counter body kinematics of industrial mills. It can utilise real production ores, can accommodate a large range of abrasive (ore) particle size distributions and produce quantitative ranked performances of different alloys. The test also allows simultaneous exposure of multiple specimens, reducing sensitivity of alloy performance to small changes in abrasive (ore) condition over time, and allowing for increased speed of data generation.

Further development of the BMA test has resulted in a procedure to predict plant ball mill media wear rates from laboratory based ball mill tests [8]. It was shown that laboratory mill tests could predict plant media wear rate to within $20 \%$. Whilst this is still a wide margin of error, this variant of the BMA test shows promise.

The BMA test is non-standardised in the sense that the reference used is the average wear rate of all the media used in the tests, and not a standard reference alloy. In principle it would seem simpler to use a single alloy grade as the standard for comparison, but in the work conducted by UQMP the collective reference was found to be less affected by statistical scatter, providing a more consistent measure of alloy performance from test to test. Obviously using the average wear rate of all media is only applicable to that group of tests. The relative performance of each media grade is then expressed as projected service life (reciprocal of wear rate) relative to the average of all the media by the formula:

$$
L_{A}=\frac{M_{R}}{M_{A}}
$$

Where $L_{A}$ is relative wear life of media grade A as predicted by the test;MA is the measured mass loss per unit surface area of media grade A, averaged over the specimens of this grade/size; and MR is the mass loss per unit surface area of the chosen reference media grade $\mathrm{R}$, or the average of a collective set of reference materials that can simulate the fracture process of materials.

In this paper, a particle flow code is used to study the shear failure behaviour of nonpersistent joint under high normal load. Also, the ability of PFC2D in determining the failure patterns in rock bridges has been checked by comparison of the numerical and experimental results. For this purpose, using an inverse-modelling calibration approach, the laboratory results of the uniaxial, Brazilian and triaxial tests were used to obtain the estimates of the intact rock micromechanical parameters used in the simulation. A validation of the simulation was then performed by comparison between the shear behaviour of rock bridges in PFC2D and that of the non-persistent joint tested under direct shear loading in the laboratory. The validated numerical model was used to further studying the mechanical behaviour of the jointed models with different joint persistency.

\section{Experimental}

A series of tests was conducted to rank the wear rates of four grades of Metso produced grinding media (R400, R300, R240 and SR). The purpose of the tests was to compare the rankings with those obtained by UQMP from their BMA test. The methodology employed was based on the BMA test and used two laboratory mills, a larger one $300 \times 300 \mathrm{~mm}$ 
(length $\mathrm{x}$ diameter), and a smaller one $250 \mathrm{x}$ $206 \mathrm{~mm}$. Personnel who were untrained in the detailed BMA test were employed to carry out the work. The ores used were basalt and river sand.

Each ball used in the tests was initially cleaned, dried, weighed to $\pm 1 \mathrm{mg}$, and its diameter (nominally $41 \mathrm{~mm}$ ) measured using calipers. Using this data the average density of each grade was calculated as shown in Table 1. The four grades of media were uniquely marked by differently orientated cuts into the ball surfaces made using a small rotary grinding tool. It was found that all the markings were maintained throughout the cleaning and test grinds, with all the balls still easily identifiable at the end of the test work.

Table 1. Mean Density of Grinding Media

\begin{tabular}{|c|c|}
\hline Media Grade & Mean Density $\mathrm{t} / \mathrm{m}^{3}$ \\
\hline R240 & 7.844 \\
\hline R400 & 7.861 \\
\hline R300 & 7.793 \\
\hline SR & 7.819 \\
\hline
\end{tabular}

In order to produce balls with clean, rust free, and uniform surfaces, the entire set of marked balls was subjected to four three-hour grinds in $-1 \mathrm{~mm}$ river sand over two days, followed by a final one hour grind in river sand on the day of the first grinding test. Fourteen successive tests were conducted in the larger mill, 10 of one hour duration (1 10 ), with two tests conducted per day and four of three hours duration $(11-14)$, with one test conducted per day. The balls were carefully stored overnight to minimize corrosion, however the ball surfaces for the first test of each day showed minor rust and staining, whilst for the second test the surfaces were clean, due to wear from the preceding test.

Accordingly the data was later analysed in terms of dirty and clean surfaces. In the case of the three hour tests, two tests used overnight stained surfaces, and for the remaining two tests the balls were first cleaned by a 30 minute grind in river sand. These tests were conducted by Operator 1 . Two tests were conducted in the smaller mill, each of three hours duration. These two tests were conducted with clean balls after a 1 hour pre-test grind in river sand. These tests were conducted by Operator 2.

The procedure for each test was as follows. Each ball was weighed to $\pm 1 \mathrm{mg}$, and 21 balls of each of the four grades of media charged to the larger mill, for a total charge mass of 22.4 $\mathrm{kg}$. Water $(2.6 \mathrm{~L})$ and $-3.5 \mathrm{~mm}$ basalt ore $(3.5$ $\mathrm{kg}$ ) were added to achieve $31.2 \%$ filling by volume and $55 \%$ solids by mass. For the smaller mill, the charge consisted of 16 balls of three different grades (R400, R300, R240), for a total mass of $12.7 \mathrm{~kg}$. Water $(0.92 \mathrm{~kg})$ and $-1.0 \mathrm{~mm}$ river sand $(1.18 \mathrm{~kg}$, used as the ore) were added to achieve $36.4 \%$ filling by volume and $55 \%$ solids by mass. The ball charge was increased in the smaller mill in order to have more than 15 balls of each grade being tested. The ore volume was also reduced to keep the total mill filling close to the test conditions employed by UQMP.

The mills were run at $66 \%$ of critical speed for the required test duration for all tests. On completion of a test, the mills were emptied, and the media separated from the slurry. Each ball was cleaned, its grade identified by the markings, dried andreweighed to $\pm 1 \mathrm{mg}$ to determine the mass loss of each grade.

\section{Results and Discussion}

Media wear was calculated on the basis of mass loss (mg) per $\mathrm{mm}^{2}$ of ball surface area per hour. Wear rate must be expressed in terms of surface area as the different grades exhibited slight differences in diameter as a result of differences in manufacture. Wear is proportional to surface area, increasing with the amount of exposed surface area. 
The difference in ball diameter after successive tests is only of the order of a few microns, and cannot be measured with sufficient accuracy by calipers to calculate the change in surface area. Hence the surface area of the balls after each test was calculated as follows. Firstly the mean volume of each grade was calculated from the mean mass and the ball density given in Table 1 . Using the equations for the volume and surface area of a sphere, the mean radius of the balls can be calculated and thus the mean surface area. The mass loss per unit of surface area in mg per $\mathrm{mm}^{2}$ per hour can then be calculated.
Figure 1 shows the wear rates for each grade for all 14 tests in the large mill, and the average wear rates for each grade are shown in Table 2. The saw tooth nature of the data clearly shows the effect of dirty compared with clean surfaces. Tests $2,4 \ldots 10$ and 13,14 started with clean surfaces, and tests $1,3 \ldots$ 9and 11, 12 started with dirty surfaces as discussed previously. The effect is more apparent in Figures 2 and 3, dirty surfaces result in higher wear rates, the ranking is also clear, with SR media showing the least wear.

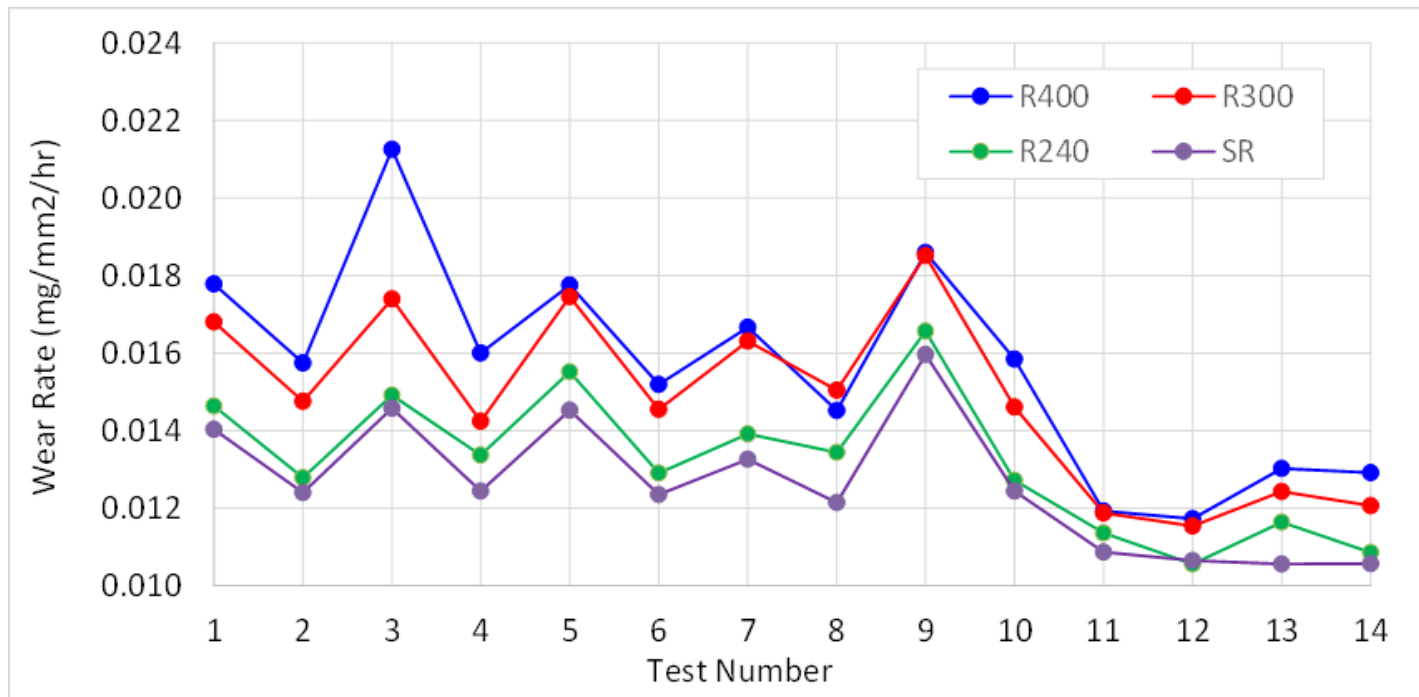

Figure 1. Wear Rates of Four Grades of Grinding Media in Successive Tests

Table 2. Average Wear Rates,Large Mill Tests $\left(\mathrm{mg} / \mathrm{mm}^{2} / \mathrm{hr}\right)$

\begin{tabular}{|l|c|c|c|c|c|}
\hline & \multicolumn{4}{|c|}{ Media Grade } & \multirow{2}{*}{$\begin{array}{c}\text { Average } \\
\text { All Grades }\end{array}$} \\
\cline { 2 - 5 } & R400 & R300 & R240 & SR & 0 \\
\hline 1 hr clean & 0.0155 & 0.0146 & 0.0130 & 0.0124 & 0.0163 \\
\hline 3 hr dirty & 0.0184 & 0.0173 & 0.0151 & 0.0145 & 0.0118 \\
\hline 3 hr dirty & 0.0130 & 0.0122 & 0.0112 & 0.0106 & 0.0113 \\
\hline
\end{tabular}

It is also clear that wear rate is lower for the three hour tests, although the ranking remains the same as for the shorter tests.
It is thought the lower wear rate is due to due to degradation and size reduction of the basalt during the longer tests. 


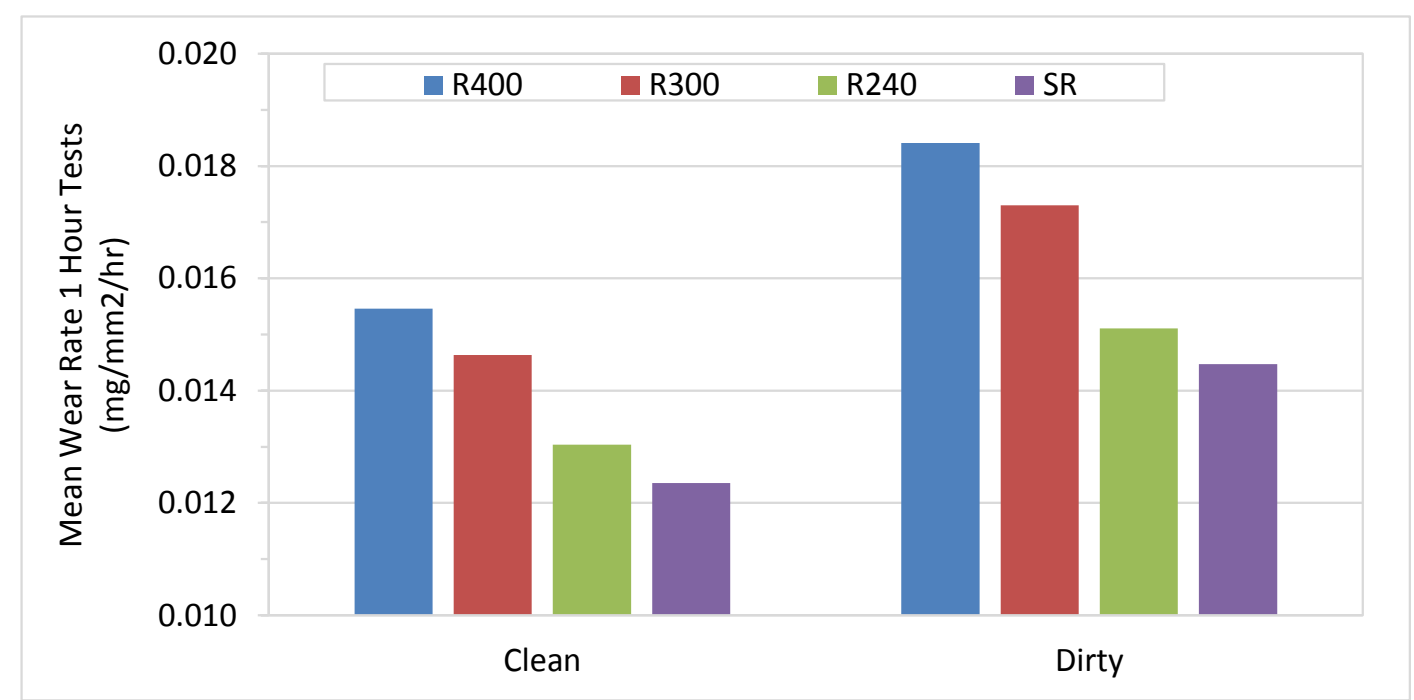

Figure 2. Effect of Surface Cleanliness on Mean Wear Rate, 1 Hour Tests

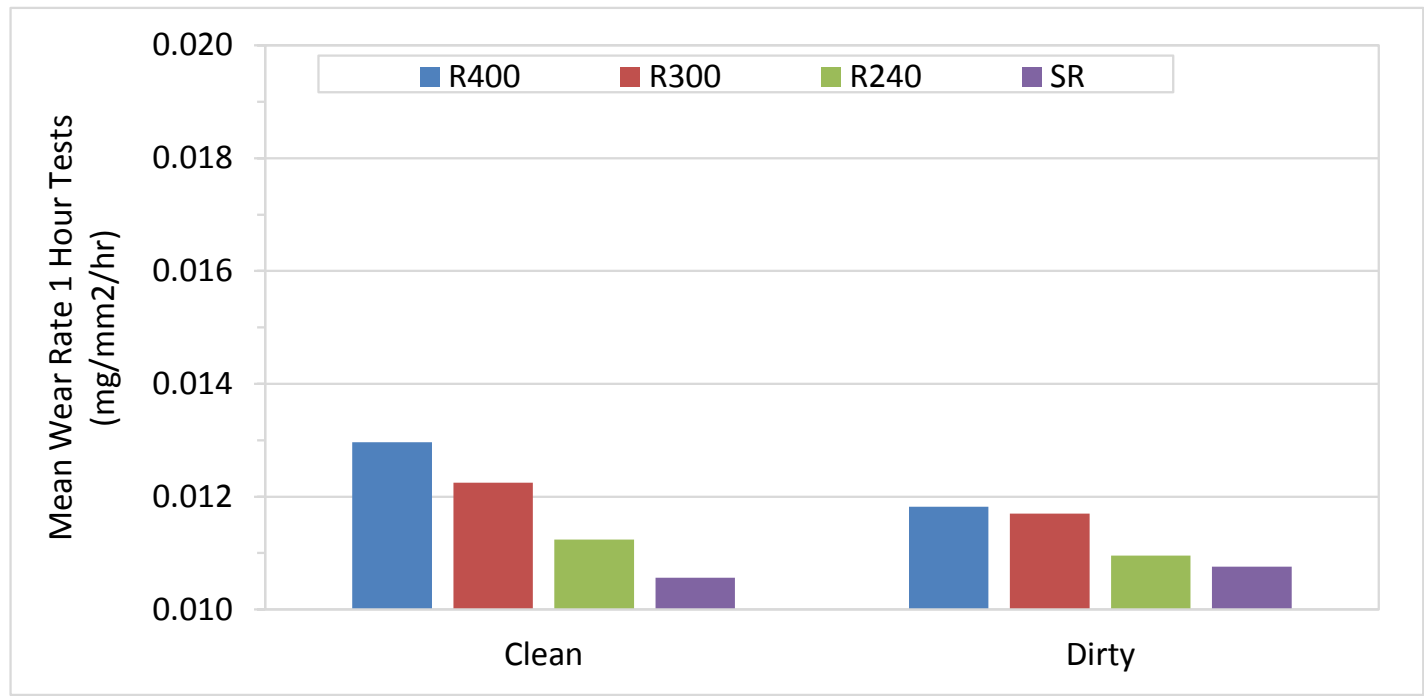

Figure 3. Effect of Surface Cleanliness on Mean Wear Rate, 3 Hour Tests

Figure 4 shows the results for the second series of two tests in the smaller mill, as noted previously both tests were conducted on clean balls. The results are given in Table 3 .

There is some difference between the results of the two tests, especially for the R400 grade. It is possible that more chipping of this grade occurred in the second test.
The wear rate in the small mill is noticeably higher for all three media grades, however the ranking of the wear rates is the same as in the larger mill.The two series of tests (large and small mill) are compared in Figure 5. In the case of the larger mill only clean balls tested for three hours (test 13 and 14) are used in the comparison. 
Table 3. Average Wear Rates,Small Mill Tests $\left(\mathrm{mg} / \mathrm{mm}^{2} / \mathrm{hr}\right)$

\begin{tabular}{|c|c|c|c|c|}
\hline & \multicolumn{3}{|c|}{ Media Grade } & \multirow{2}{*}{ Average } \\
\cline { 2 - 4 } & $\mathrm{R} 400$ & $\mathrm{R} 300$ & $\mathrm{R} 240$ & \\
\hline Test 1 & 0.0186 & 0.0178 & 0.0162 & 0.0175 \\
\hline Test 2 & 0.0256 & 0.0165 & 0.0150 & 0.0190 \\
\hline
\end{tabular}

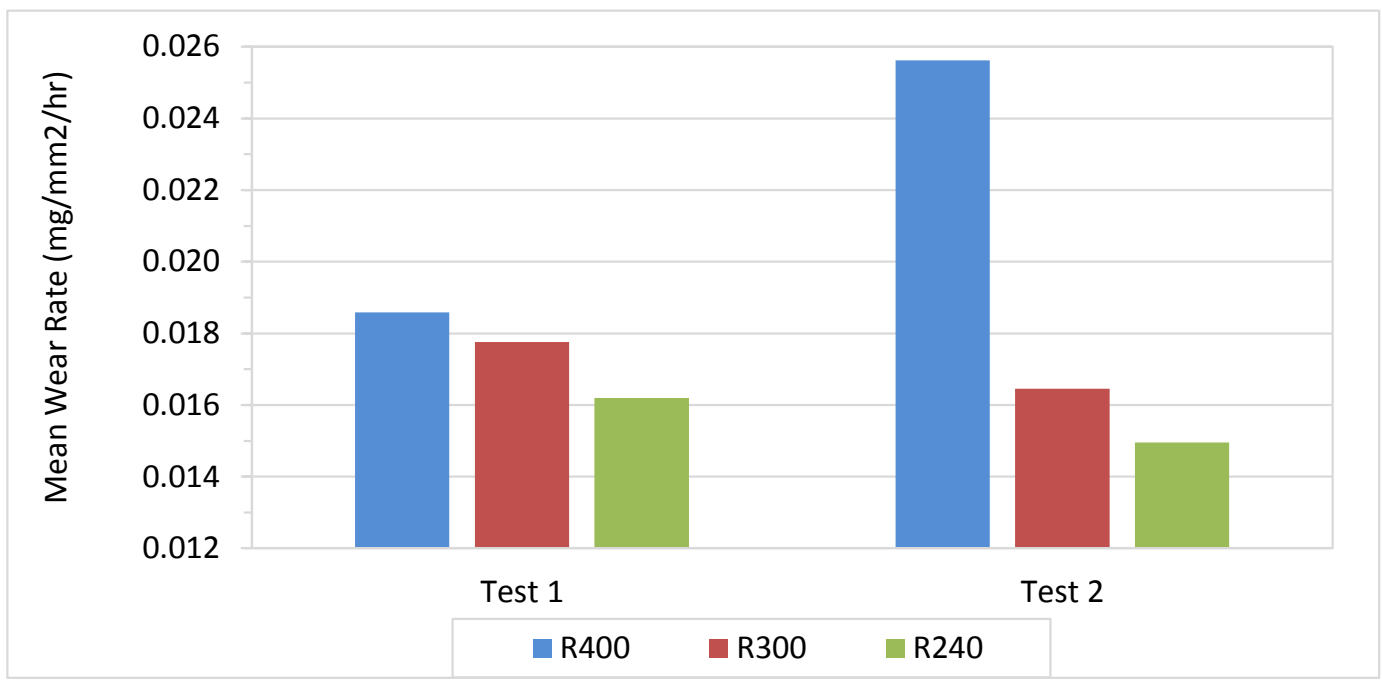

Figure 4. Wear Rates in the Small Mill

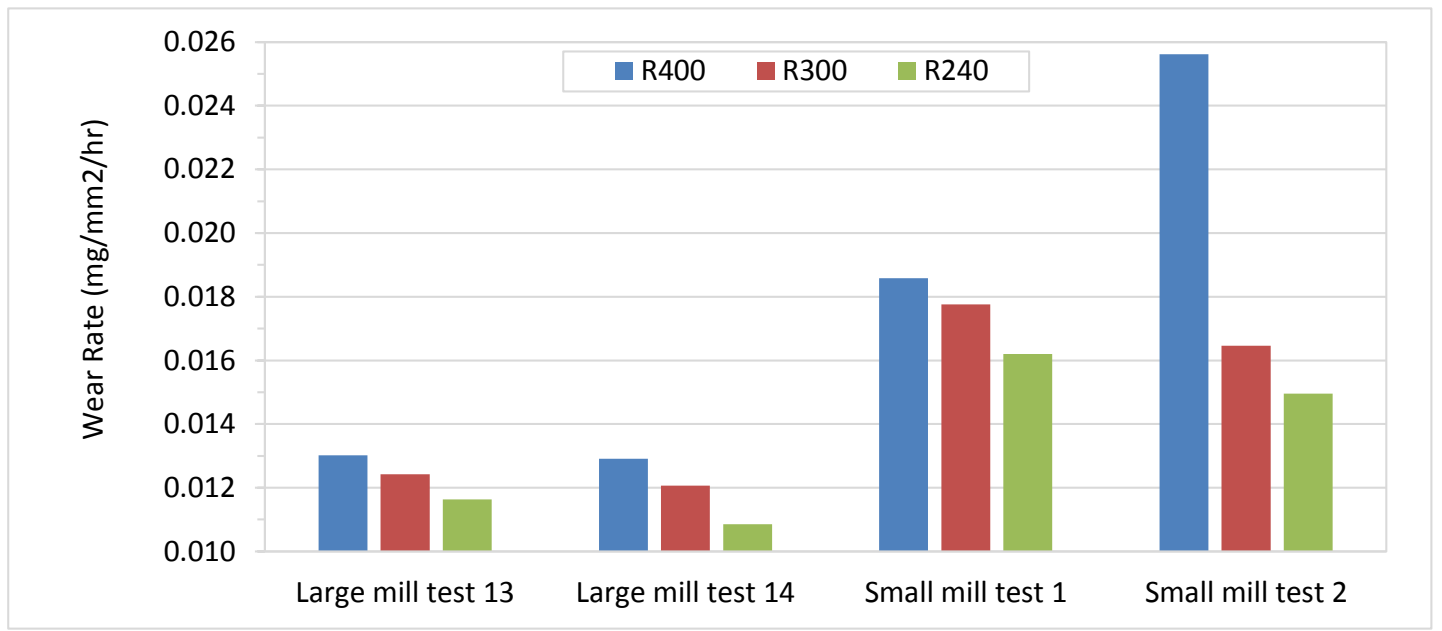

Figure 5. Comparison of Wear Rates from Large Mill and Small Mill Tests

The relative wear life calculated from Equation 1 is shown in Figure 6 for the one hour tests and Figure 7 for the three hour tests in the larger mill, compared with the results from the UQMP BMA test. The data shown in Table 2 was used, where for example the relative wear life of R400 in the one hour test in the large mill is given by the average wear rate of all the tests $\left(0.0139 \mathrm{mg} / \mathrm{mm}^{2} / \mathrm{h}\right)$ divided by the wear rate for R400 $(0.0155$ $\mathrm{mg} / \mathrm{mm}^{2} / \mathrm{h}$ ). It is clear that the ranking obtained by the test wok described here is the 
same as obtained by UQMP, however the UQMP BMA test suggests that the difference in wear life between the four grades of media is more marked. The difference between clean and dirty initial surfaces is less apparent. The relative wear life for the two tests using the smaller mill is shown in Figure 8, again the ranking agrees with the UQMP BMA test. However there is more variation in the results between the two tests, suggesting that the smaller mill may not be as suitable for conducting wear tests.

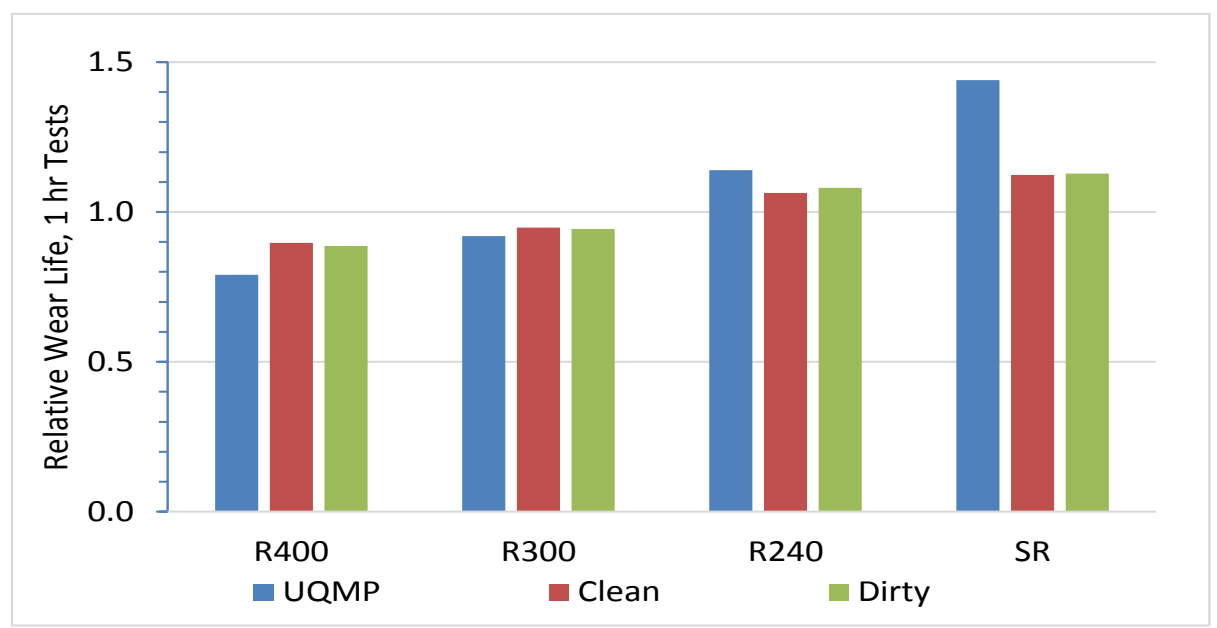

Figure 6. Relative Wear Life, One Hour Tests, Compared with UQMP Results

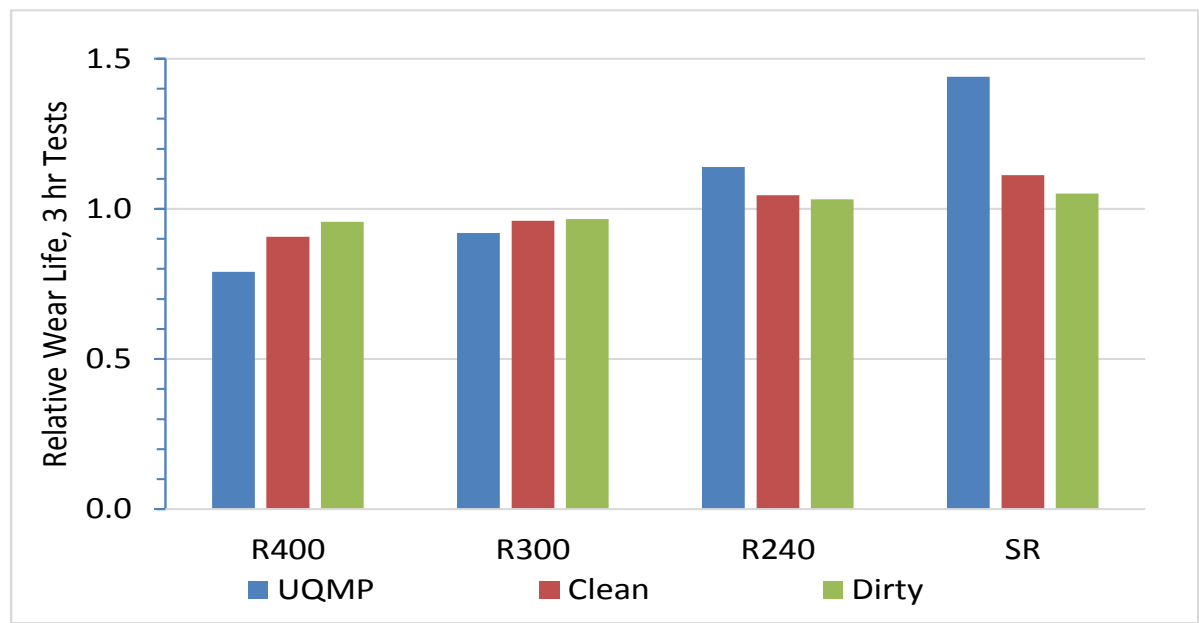

Figure 7. Relative Wear Life, One Hour Tests, Compared with UQMP Results

\section{Conclusions}

The conclusions from the test work described here are as follows. Results from the UQMP Ball Mill Wear test can be reproduced using readily available small laboratory grinding mills and untrained personnel and the same rankings obtained between different grades of media. However, the absolute wear rates of the media in industrial application cannot be reliably determined. Corrosion of the ball surfaces after overnight storage has a marked effect on the wear rates observed. 
There was a significant difference in the results obtained from the larger mill when compared with the results from the smaller mill, however the tests were conducted with different ores which may account for much of the difference.

Wear rates in the larger mill were lower for the three hour tests compare with the one hour tests. This may be due to the ore becoming to fine to act as an abrasive during prolonged grinding.

\section{Acknowledgements}

The authors appreciate the funding provided for this research project by Metso Minerals. We are grateful to Peter Holtham for his contributions and comments on the manuscript. Jeff Gates from UQMP is acknowledged for his technical support and the contributions of his expertise.

\section{References}

[1] Meulendyke, M.J, Purdue, J.D. (1989) Wear of grinding media in the mineral processing industry: an overview, SME Annual Meeting, Las Vegas, Nevada February 27-March 2, 1989.

[2] Moema, J.S, Papa, M.J, Slabbert, G.A, Zimba, J. (2009) Grinding media quality assurance for the comminution of gold ores, World Gold Conference 2009, The Southern African Institute of Mining and Metallurgy.

[3] Dunn, D.J. (1989) Design of grinding balls, SME-AIME Transactions, Mining Engineering.

[4] Bond, F.C. (1963) Metal wear in crushing and grinding, 54 ${ }^{\text {th }}$ Annual Meeting of American Institute of Chemical Engineers, Houston Texas.

[5] Aldrich, C. (2013) Consumption of steel grinding media in mills - A review, Minerals Engineering, 49, 77-91.
[6] Bennet, P.J, Gates, J.D. (2014) Mill Media Research Phase 04 - Effect of Corrosion on Wear Performance of Cast Chrome-Iron vs Forged Low-Alloy Steel Media, Internal Report, University of Queensland Materials Performance Group, (unpublished).

[7] Gates, J.D, Dargusch, M.S, Walsh, J.J, Field, S.L, Hermand, M.J, Delaup, B.G, Saad, J.R. (2008) Effect of abrasive mineral on alloy performance in the ball mill abrasion test, Wear 265, 865-870

[8] Gates, J.D, Giblett, A, Dunne, R. (2012) Prediction of plant ball mill media wear rates from laboratory ball mill test data, Comminution '12, Minerals Engineering. 


\title{
UPOREĐIVANJE BRZINE HABANJA MELJUĆIH TELA KOD MLINOVA SA KUGLAMA
}

\author{
A. Jankovic ${ }^{\#}$ T. Wills, S. Dikmen \\ Metso Process Technology and Innovation, Brisbane, Australia \\ Queensland Centre for Advanced Technologies, 1 Technology Court, \\ Pullenvale, QLD 4069 Australia
}

(Primljen: 4. Februar 2016.; Prihvaćen: 4. Novembar, 2016.)

\begin{abstract}
Izvod
Test abrazije mlina sa kuglama (Ball Mill Abrasion test - BMA) je razvijen na University of Queensland Materials Performance group kako bi se simulirali uslovi abrazije u mlinovima sa kuglama u proizvodnji. Test daje preciznu prognozu veka trajanja legura otpornih na habanje koje se primenjuju za izradu obloga i meljućih tela mlinova.U ovom radu BMA test je primenjen kako bi se istražile brzine habanja meljućih tela četiri različita kvaliteta koristeći dva laboratorijska mlina sa kuglama. Vrednosti dobijene ovim testovima su identične vrednostima dobijenim punim BMA testom mada razlika između pojedinih kvaliteta nije odgovarala naynačenim. Zaključak je da $i$ neobučeno ljudstvo možr primeniti ovu proceduru u maloj razmeri kako bi odredilo relativne ali ne i apsolutne brzine habanja meljućih tela.
\end{abstract}

Ključne reči: meljuća tela; brzina habanja; test abrazije mlina sa kuglama.

\footnotetext{
${ }^{\#}$ Kontakt adresa autora: alex.jankovic@metso.com
} 